\title{
Modeling and Detailed design of the Hand Prosthesis Promanu
}

\author{
Jair L. Loaiza B. ${ }^{1}$, Nelson Arzola ${ }^{2}$ and Ruben D. Hernández B.,** \\ ${ }^{1}$ Department of Mechanical Engineering, America University, Bogotá, Colombia. \\ ${ }^{2}$ Department of Mechanical and Mechatronics Engineering, National University of Colombia Bogotá, Colombia. \\ ${ }^{3}$ Department of Biomedical Engineering, Military Nueva Granada University Bogotá, Colombia.
}

Received 10 January 2020; Accepted 5 May 2020

\begin{abstract}
This paper presents the process of modeling and detailed design of the prosthetic hand Promanu. The kinematic model, generated by transformation matrices guarantees the six degrees of freedom required to achieve the common movements gripping and manipulating objects. Consist of rotating finger phalanges driven by wires during closing and during the opening by linear elastomer springs. The thumb has two degrees of freedom, facilitating the movement of opposition to the other fingers; the index finger has a degree of freedom and fingers another degree of freedom. The wrist has flexionextension movement $\left( \pm 85^{\circ}\right)$ using a kinematic pair consisting of a mini-motor. While forearm pronation has supination by rotation $\left( \pm 105^{\circ}\right)$ of two moving parts driven by a mini-motor. To ensure conditions of strength and stiffness of the prosthesis develop dynamic simulations using the finite element method. The grips of a cylinder, a block and a small sphere are studied. The detailed design is evaluated by reviewing the kinematic and dynamic performance analysis of resistance and rigidity achieved, verifying the adequacy of the actuators, checking the conditions of understanding and other attributes set design by Quality function deployment (QFD). As a result, a functional prototype prosthetic hand is obtained using the technique of rapid prototyping, which meets the required design specifications and is projected as an attractive solution for amputee patients.
\end{abstract}

Keywords: Prosthetic hand, dynamic modeling, kinematics, phalanx, understanding.

\section{Introduction}

Design a device that can replace all the functions of a human hand is an engineering challenge has been trying to make. However, the application of computational tools for geometric and dynamic modeling of the prosthetic hand is comparatively time, relatively recent. The need for mathematical and geometric models of the human hand arose in response to the requirements of electrical and electronic control, which was applied to the $60 \mathrm{~s}$ with the emergence of the first myoelectric prosthesis control Russia [1]. Prior to this, the geometric analysis was used almost exclusively for ensuring the anthropometry of the prosthesis, so that the dimensional and morphologically approaching this as much as possible to the appearance of a real upper extremity. Currently, mathematical models created to describe the function of the hand are proportionally more complex depending on what the functional characteristics desired in the prosthesis. Because the hand is the primary tool with which the human mind, both for routine tasks at work and to express feelings, Creative manifestations and defence, even there does not know himself a model who covers all the potentials of this extremity from the cinematic and dynamic point of view. Some models centre on describing the tweezer tridigital, on which they control only three fingers (index, heart and thumb) [2], so you can limit the number of links involved, without drastically reducing the number of applications required to remain functional the prosthesis.

*E-mail address: ruben.hernandez@unimilitar.edu.co ISSN: 1791-2377 @ 2020 School of Science, IHU. All rights reserved. doi:10.25103/jestr.133.14
Those models that describe both the movement of all fingers with phalanges and flexion-extension of the wrist and forearm rotation are designed from the matrix algebra [3], such as the representation of Denavit-Hartenberg, which is widely used in the description of the robotic arms [4], [5]. Other models make use of the characteristics of some types of programs CAD-CAM-Simulation (Design, Manufacturing and Computer Aided Simulation), for through modeling, find expressions relating the behaviour of the links with different design attributes that are intended for the prosthesis [6]. Both algebraic descriptions as those obtained through modeling, set the shape and strength requirements to be applied in the detailed design of the prosthesis.

In this work the process of modeling and detailed design of the prosthetic hand Promanu presented. Initially a vector model to describe the movements of the seven degrees of freedom required to achieve the common shares gripping and manipulating objects using rotation matrices is proposed. This model is programmed into the Matlab ${ }^{\circledR}$ software; in order to establish the geometric and kinematic variables are then used in the construction of the CAD model, keeping the dimensional correspondence and restrictions on movements. The evaluation of the CAD model through SolidWorks Motion ${ }^{\circledR}$ tool identifies the closeness of the vector kinematic model and the results obtained from the simulation. This defines the kinematics of the prosthesis can then evaluate the strength and stiffness achieved for engineering materials proposed by the tool finite element analysis software Solidworks ${ }^{\circledR}$ thereof, simulating the grip of an object cylindrical. Finally, it is a functional prototype generated by the rapid prototyping technique to experimentally test the mechanical behavior of the prosthesis. 


\section{Kinematic Model Approach}

The kinematic model is proposed in order to make the first assessment of performance, according to the design specifications. This model is constructed from a vector description of the hand, from a global reference system anchored to the palm. The kinematic model developed can be extended to all fingers. However, it is proposed in the next job only for the middle finger. Figure 1 graphically shows the reference systems and vectors used. It should be noted that the system formed by the axis $\boldsymbol{x}_{\boldsymbol{1}}, \boldsymbol{y}_{1}$ and has moved on the medial phalanx, using $\boldsymbol{z}_{1}$ as the rotation axis, this means that while $\boldsymbol{x}_{1}$ and $\boldsymbol{y}_{1}$ change position in a time interval $(t)$ given, $\boldsymbol{z}_{l}$ remains invariant relative to said phalanx. Likewise, the middle phalanx having relative rotational movement to the proximal phalanx, where $\boldsymbol{z}_{2}$ axis acts in the same manner as $\boldsymbol{z}_{1}$ in the above description, but this time in the medial-proximal joint, $\boldsymbol{y}_{2}$ and $\boldsymbol{x}_{2}$ in the change position time. Finally, the proximal phalanx moves on the carpal and $z_{3}$ is the rotation axis. Therefore, $\boldsymbol{z}_{i}$ axes always remain parallel to any position of the phalanges.

According to Figure 1, the vector $\boldsymbol{r}_{1}$ corresponds to the distal phalanx, the vector $\boldsymbol{r}_{2}$ to the medial phalanx vector to the proximal phalanx $\boldsymbol{r}_{3}$ and $\boldsymbol{r}_{4}$ vector corresponding metacarpal bone. The angle of rotation about $\boldsymbol{r}_{1}, \boldsymbol{r}_{2}$ is named $\boldsymbol{\alpha}$, the corresponding between $\boldsymbol{r}_{2}$ and $\boldsymbol{r}_{3}$, and finally $\boldsymbol{\beta}$ between $\boldsymbol{r}_{3}$ and $\boldsymbol{r}_{4}, \boldsymbol{\gamma}$. From the description of the biomechanics of the hand [7], it is known that the rotation angles relative between phalanges vary between $0^{\circ}$ and $90^{\circ}$, thus this varied range for $\boldsymbol{\alpha}, \boldsymbol{\beta}$ and $\boldsymbol{\gamma}$ are set, and values for the lengths $\boldsymbol{r}_{1}, \boldsymbol{r}_{2}, \boldsymbol{r}_{3}$ and $\boldsymbol{r}_{4}$ vectors corresponding to the phalanges and the metacarpal, are also taken from [7]. With the support of Figure 1 can be constructed that rotation matrices relate the motion between the vectors.

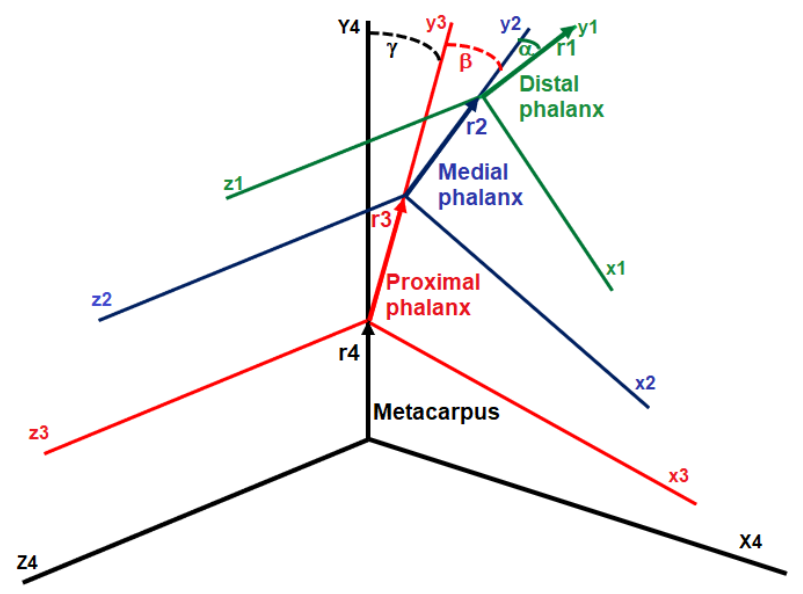

Fig. 1. Vector Description finger (middle).

$$
\begin{aligned}
& \left.r_{1}=\left[\begin{array}{lll}
0 & r_{1} & 0
\end{array}\right]_{\left(x_{1}\right.} y_{1} \quad z_{1}\right) \\
& r_{a}=r_{2}+r_{1 / 2}=r_{2}+r_{1} \cdot \alpha
\end{aligned}
$$

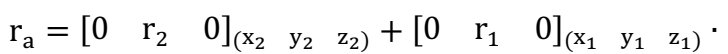

$$
\begin{aligned}
& {\left[\begin{array}{ccc}
\cos (\alpha) & -\operatorname{sen}(\alpha) & 0 \\
\operatorname{sen}(\alpha) & \cos (\alpha) & 0 \\
0 & 0 & 0
\end{array}\right]}
\end{aligned}
$$

Where $\underline{\boldsymbol{r}}_{a}$ corresponds to the vector describing the position of the end point $\boldsymbol{r}_{1}$ from the origin of the reference system $\left(\boldsymbol{x}_{2}\right.$, $\left.\boldsymbol{y}_{2}, \boldsymbol{z}_{2}\right)$ in (3). The arrangement shown corresponds to the rotation matrix for angle $\alpha$. Following the above procedure, one has then.

$$
\begin{aligned}
& \mathrm{r}_{\mathrm{b}}=\mathrm{r}_{3}+\mathrm{r}_{\mathrm{a} / 3}=\mathrm{r}_{3}+\mathrm{r}_{\mathrm{a}} \\
& \left.\mathrm{r}_{\mathrm{b}}=\left[\begin{array}{lll}
0 & \mathrm{r}_{3} & 0
\end{array}\right]_{\left(\mathrm{x}_{3}\right.} \mathrm{y}_{3} \mathrm{z}_{3}\right)+\left[\mathrm{r}_{\mathrm{a}}\right] . \\
& {\left[\begin{array}{ccc}
\cos (\beta) & -\operatorname{sen}(\beta) & 0 \\
\operatorname{sen}(\beta) & \cos (\beta) & 0 \\
0 & 0 & 0
\end{array}\right]}
\end{aligned}
$$

Where $\underline{\boldsymbol{r}}_{\boldsymbol{b}}$ is the position vector $\mathrm{r}_{1}$ endpoint on the origin of the coordinate system $\left(x_{3}, y_{3}, z_{3}\right)$ in (5). Again, the matrix shown in (5) corresponds to the rotation caused by the change $\boldsymbol{\beta}$. Finally,

$$
\begin{aligned}
& r_{c}=r_{4}+r_{b / 4}=r_{4}+r_{b} \\
& r_{c}=\left[\begin{array}{llll}
0 & r_{4} & 0
\end{array}\right]_{\left(x_{4}\right.} y_{4} \\
& \left.z_{4}\right) \\
& {\left[\begin{array}{ccc}
\cos (\gamma) & -\operatorname{sen}(\gamma) & 0 \\
\operatorname{sen}(\gamma) & \cos (\gamma) & 0 \\
0 & 0 & 0
\end{array}\right] .}
\end{aligned}
$$

In (7), $\underline{\boldsymbol{r}}_{c}$ corresponds to the end position vector $\boldsymbol{r}_{1}$ seen from the coordinate system $\left(\boldsymbol{x}_{4}, \boldsymbol{y}_{4}, \boldsymbol{z}_{4}\right)$ and the matrix corresponds to the rotation produced by $\gamma$.

Because the variation range for $\boldsymbol{\alpha}, \boldsymbol{\beta}$ and $\boldsymbol{\gamma}$ is the same $\left(\boldsymbol{0}^{\circ}\right.$ to $90^{\circ}$ ), and assuming that variation happens in the same time interval for three phalanges when the finger closes or opens, the same functions of angular position $(\boldsymbol{\theta})$, angular velocity $(\dot{\boldsymbol{\theta}})$ and angular acceleration $(\ddot{\boldsymbol{\theta}})$ for the three angles are used. These functions are,

$$
\begin{aligned}
& \theta(\mathrm{t})=\frac{7 \mathrm{E}-16}{12} \cdot \mathrm{t}^{4}-\frac{0,1508}{6} \cdot \mathrm{t}^{3}+\frac{0.377}{2} \cdot \mathrm{t}^{2}, \text { where, } \theta(0)= \\
& 0, \theta(5)=\frac{\pi}{2} \text { or } 1,57079 \mathrm{rad} \\
& \dot{\theta}(\mathrm{t})=\frac{7 \mathrm{E}-16}{3} \cdot \mathrm{t}^{3}-\frac{0,1508}{2} \cdot \mathrm{t}^{2}+0.377 \cdot \mathrm{t} \text { where } \dot{\theta}(0)= \\
& 0 \frac{\mathrm{rad}}{\mathrm{s}}, \dot{\theta}(5)=0 \frac{\mathrm{rad}}{\mathrm{s}} \\
& \ddot{\theta}(\mathrm{t})=7 \mathrm{E}-16 \cdot \mathrm{t}^{2}-0,1508 \cdot \mathrm{t}+0.377 \text { where } \ddot{\theta}(0)= \\
& 0.377 \frac{\mathrm{rad}}{\mathrm{s}^{2}}, \ddot{\theta}(5)=-0.377 \frac{\mathrm{rad}}{\mathrm{s}^{2}}
\end{aligned}
$$

Where $\boldsymbol{t}$ is the time, which varies from $\mathbf{0}$ to $\mathbf{5 s}$.

Equations $(8,9,10)$ were established for an average of $\mathbf{5 s}$ time due to the difficulty that would involve trying to imitate the actual time when the human hand can open and close on his palm. These times are variable and depend on the action that the hand is in progress. The man in the prime of conditions can open and close the hand in less than a second while the prosthesis on the market perform this operation at a time ranging from 5 to 10 seconds [7], [8] depending on the type of device, their manufacture and specific objectives. Five seconds time is considered by the authors a decision in line with the objectives set for this design.

\section{Simplified CAD Model}

Once the kinematic and geometric design, it is passed for the construction of a simplified CAD model. In this case, the model is built in SolidWorks software. Figure 2 shows the result of this process of geometric design. The dimensions are taken from model [9]. In the case of the metacarpals $\left(\boldsymbol{r}_{4}\right.$ in 
Figure 1), because these are the palm, it was decided to take the four bones belonging to each finger and represent them as a single rigid body (purple in Figure 2), and on this the proximal, medial and distal phalanges are coupled respectively.

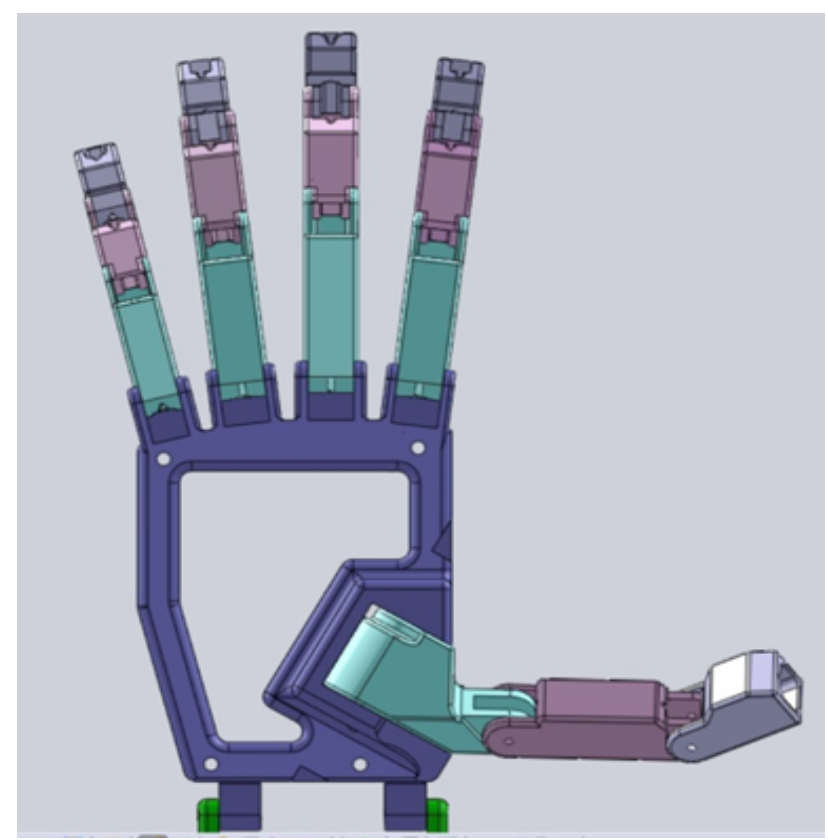

Fig. 2. Simplified CAD model. SolidWorks ${ }^{\circledR}$.

\section{Strength of Materials Analysis to a Finger}

Using the CAD model described in the previous section, an analysis is performed by resistance of materials using SolidWorks $\AA$ Simulation $\AA$. It is configured to modeling CAD system to simulate the support would make this finger when the hand was clutching a cylinder $70 \mathrm{~mm}$ in diameter, placing forces in the phalanges of the way the tendons are exercised. In the case considered here, the tendons are emulated by an inextensible cable that is ideally located within each of the phalanges (Figure 3). Because the flexor tendons of the fingers can exert forces ranging from 12.5 to $120 \mathrm{~N}$ [9], depending on the application, it is necessary to establish an average net force to apply via cable on the phalanges. The net force of $50 \mathrm{~N}$ is established for the cable tension, which as shown, is supposed located inside the phalanges through ducts built into them. This force is decomposed into two rectangular components, a force parallel to the contact force between each phalanx and the cylinder; and the other perpendicular to the previous force directed from the phalanx to the cylinder, which is causing the effective grip.

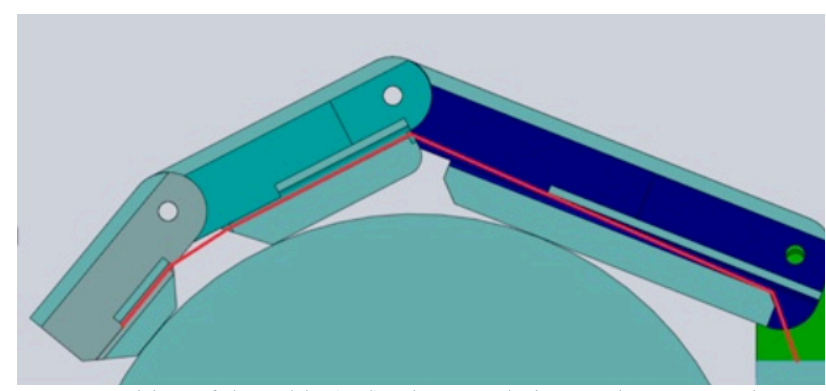

Fig. 3. Position of the cable (red) when emulating tendons act on the phalanges during flexion for gripping a cylinder of $70 \mathrm{~mm}$ diameter. SolidWorks ${ }^{\circledR}$.

\section{Results and Discussions}

Then the process of modeling and detailed design of the prosthetic hand Promanu occurs. By transformation matrices, a kinematic model of six degrees of freedom developed, required to achieve the common movements gripping and manipulating objects. The index, middle, ring and little fingers each have three phalanges which are operated by cables to bend and return to their original condition by elastomeric springs. The thumb has two degrees of freedom, including the movement of opposition to the other fingers. The doll has flexion and extension $\left( \pm 85^{\circ}\right)$ and finally has forearm pronation-supination by rotation $\left( \pm 105^{\circ}\right)$ of its two moving parts driven by a mini-motor. Develop dynamic simulations using the finite element method, and detailed design is evaluated by reviewing the kinematic and dynamic performance, analysis of the strength and rigidity achieved, verification of the relevance of the actuators, checking the grip conditions and other attributes set design by deploying the quality function.

The matrix approach described in the previous section and its implementation is on Matlab ${ }^{\circledR}$ shown below, wherein the sequence of images in Figure $4(\mathrm{a}, \mathrm{b}$ and $\mathrm{c})$ shows the movement of closing of the product hand programming (7), (8) and (9) on the same software. Lines colors, blue, green, red and cyan correspond to the index, middle, ring and little finger respectively, the broken line violet it is the thumb.

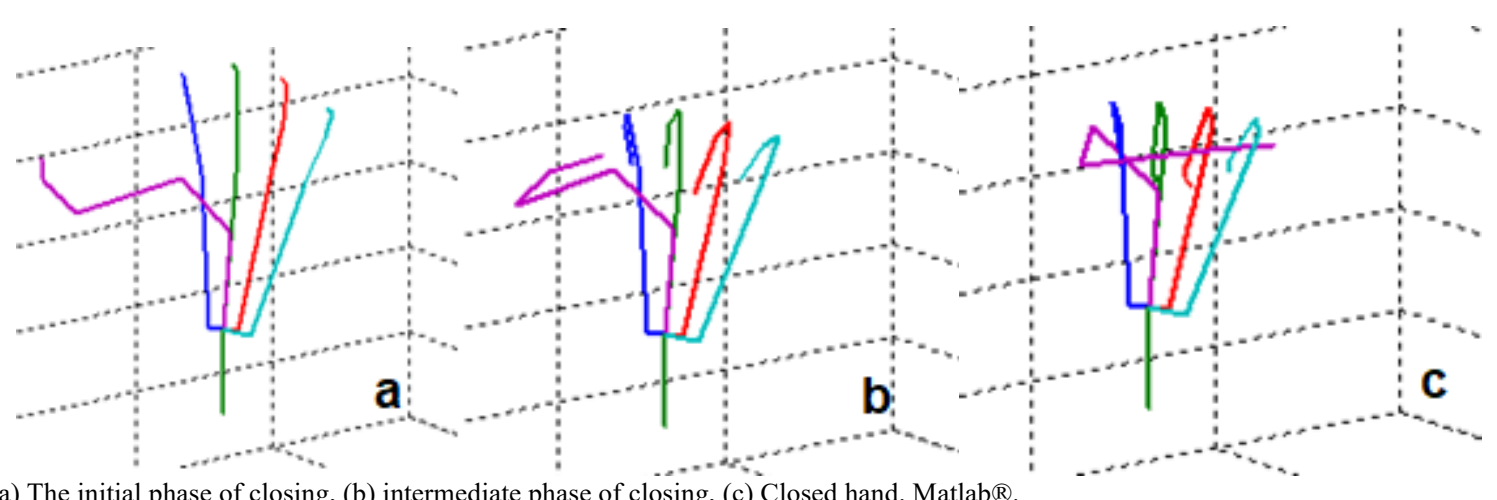

Fig. 4. (a) The initial phase of closing, (b) intermediate phase of closing, (c) Closed hand. Matlab®.

In addition to this result, it is also possible to model the closing of the hand on a cylinder with a diameter of $70 \mathrm{~mm}$, shown in the sequence of Figure 5 ( $a, b$ and $c)$. However, this model is used to compare it with the one obtained in
Solidworks ${ }^{\circledR}$ for the same operation since it was not possible to simulate the contact between the fingers and the cylinder by means of Matlab ${ }^{\circledR}$ due to the difficulty that is presented in the contact between the two chosen materials. 


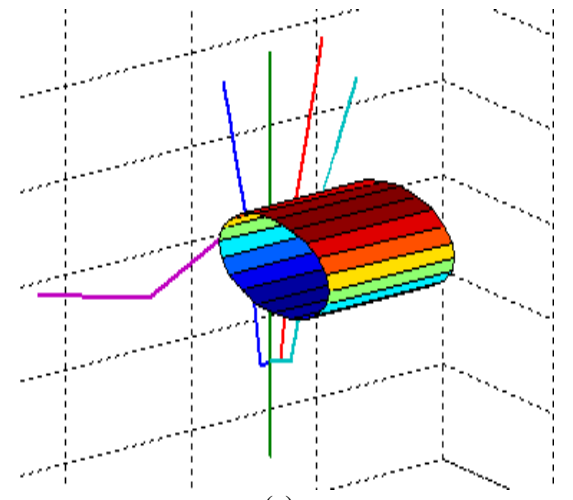

(a)

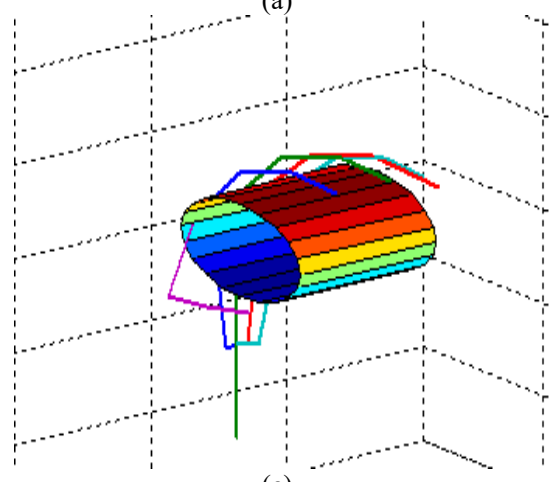

(c)

Fig. 5. Simulation of the grip of a cylinder with a diameter of $70 \mathrm{~mm}$. Matlab®)

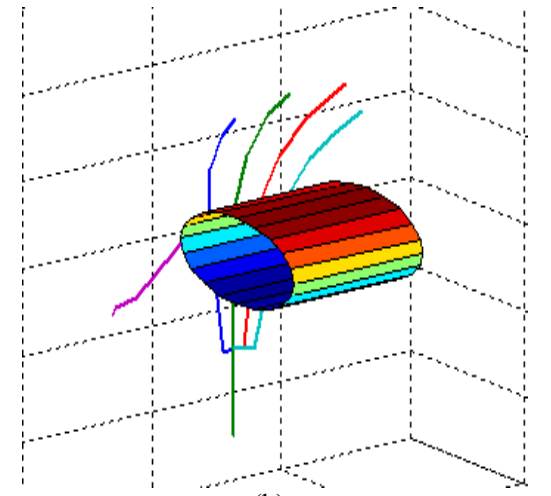

(b)

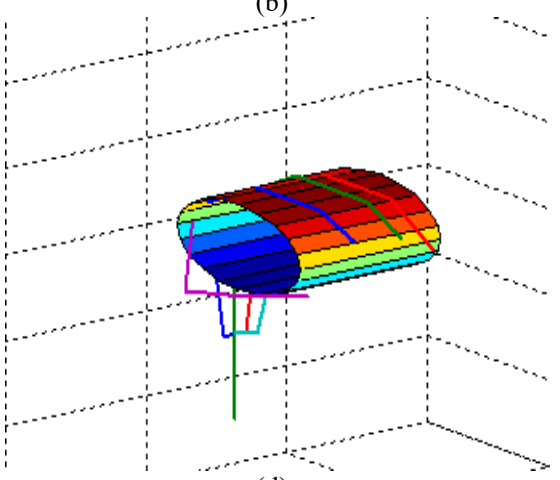

(d)
Based on this modeling, the CAD design is constructed using SolidWorks ${ }^{\circledR}$ and initially simulating the grip of the 70 mm diameter cylinder. Figures $6(\mathrm{a}, \mathrm{b}$ and $\mathrm{c})$ shows the curves of the kinematic variables, angular position, angular velocity and angular acceleration calculated in Motion $\mathbb{R}$ and plotted using MatLab®.

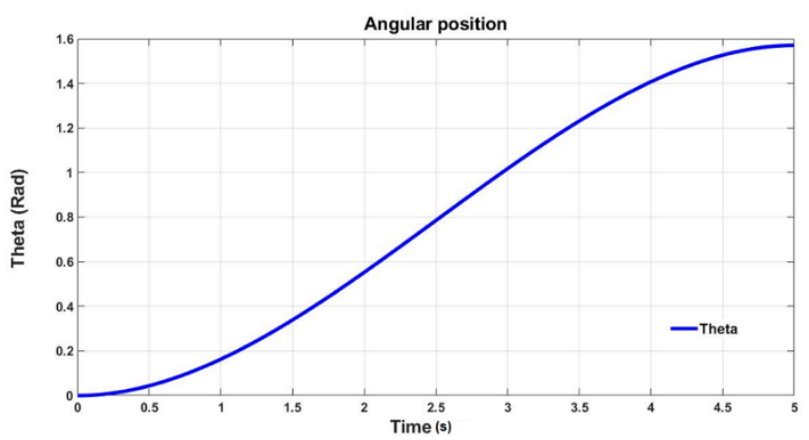

a. Angular position (Eq. 8). MatLab® .

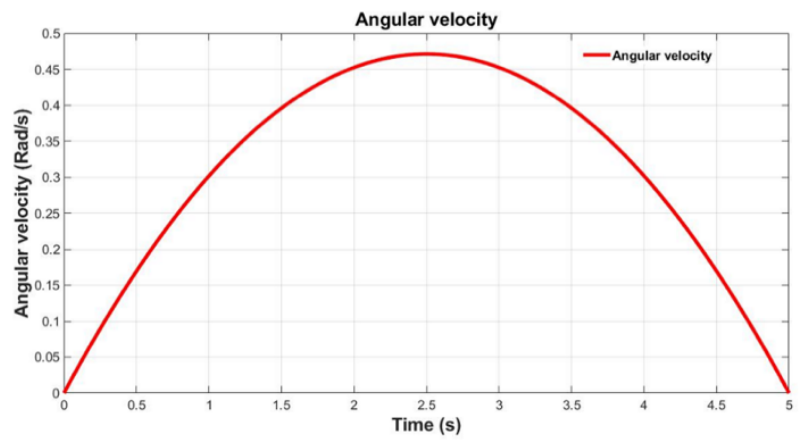

b. Angular velocity (Eq. 9). MatLab®.

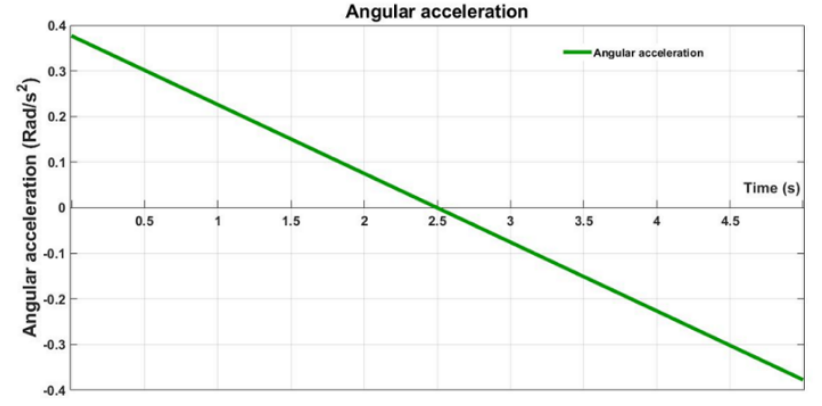

c. Angular acceleration (Eq. 10). MatLab®.

Fig. 6. Angular movements for grip of a cylinder.

\section{a. Resistance Analysis}

Material resistance design evaluation is performed using the Solidworks ${ }^{\circledR}$ Simulation ${ }^{\circledR}$ tool. For this purpose, the forces developed during the gripping of a $70 \mathrm{~mm}$ diameter 1020 steel cylinder were evaluated. The material of which the prosthesis is simulated is Nylon 6/10. Table 1 shows the properties of materials referenced in the software materials library. Since more than $80 \%$ of the force developed during a gripper is due to the gripper performed by the index, middle and thumb fingers, called the tridigital gripper, the results of the analysis shown here correspond precisely to this type of gripper. Figure 8 ( $a$ and $b$ ) shows a simplified configuration of the proposed design.

Table 1. Properties of the materials chosen for simulation.

\begin{tabular}{c|c|c|c|c|c}
\hline $\begin{array}{c}\text { Mater } \\
\text { ial }\end{array}$ & $\begin{array}{l}\text { Elastic } \\
\text { ity } \\
\text { modul } \\
\text { us (E) }\end{array}$ & $\begin{array}{c}\text { Shear } \\
\text { modul } \\
\text { us (G) }\end{array}$ & $\begin{array}{c}\text { Ratio } \\
\text { of } \\
\text { Poiss } \\
\text { on (v) }\end{array}$ & $\begin{array}{c}\text { Densi } \\
\text { ty }\end{array}$ & $\begin{array}{c}\text { Elastic } \\
\text { Limit }\end{array}$ \\
\hline Steel & $2.1 \mathrm{E} 11$ & $7.9 \mathrm{E} 1$ & 0.28 & 7800 & $220.6 \mathrm{E} 6 \mathrm{~N}$ \\
AISI & $\mathrm{N} / \mathrm{m}^{2}$ & $\begin{array}{c}0 \\
\mathrm{~N} / \mathrm{m}^{2}\end{array}$ & & $\mathrm{~kg} / \mathrm{m}^{3}$ & $/ \mathrm{m}^{2}$ \\
1020 & & & &
\end{tabular}




\begin{tabular}{c|c|c|c|c|c} 
Nylon & $8.3 \mathrm{E} 9$ & $3.2 \mathrm{E} 9$ & 0.28 & 1400 & $139 \mathrm{E} 6$ \\
$6 / 10$ & $\mathrm{~N} / \mathrm{m}^{2}$ & $\mathrm{~N} / \mathrm{m}^{2}$ & & $\mathrm{~kg} / \mathrm{m}^{3}$ & $\mathrm{~N} / \mathrm{m}^{2}$ \\
\hline
\end{tabular}

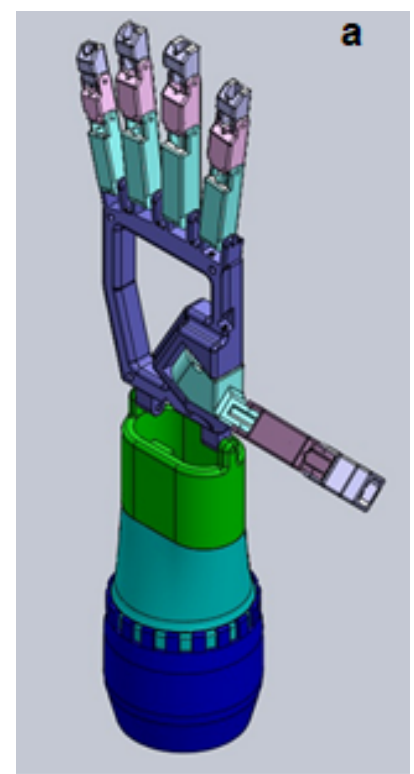

Fig. 7a and 7b. Movements of the initial stage of a cylinder grip. Solid Works ${ }^{\circledR}$.

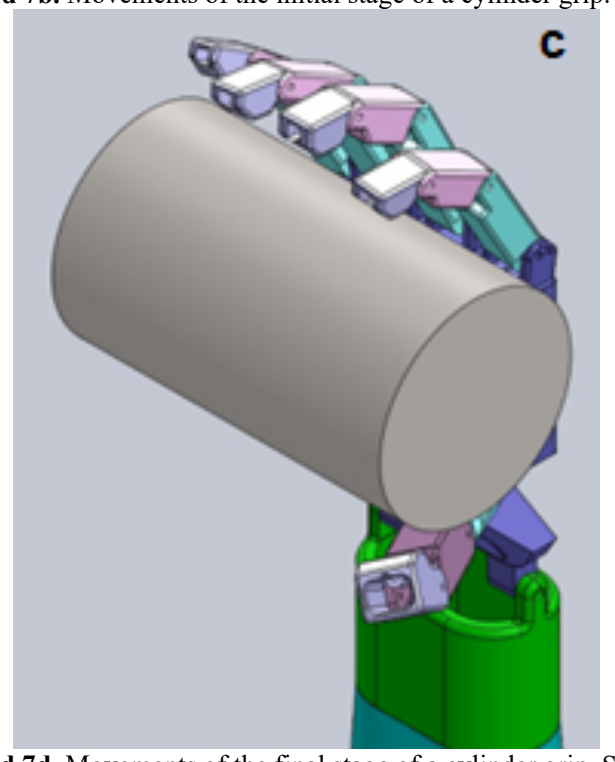

Fig. 7c and 7d. Movements of the final stage of a cylinder grip. Solid Works ${ }^{\circledR}$.

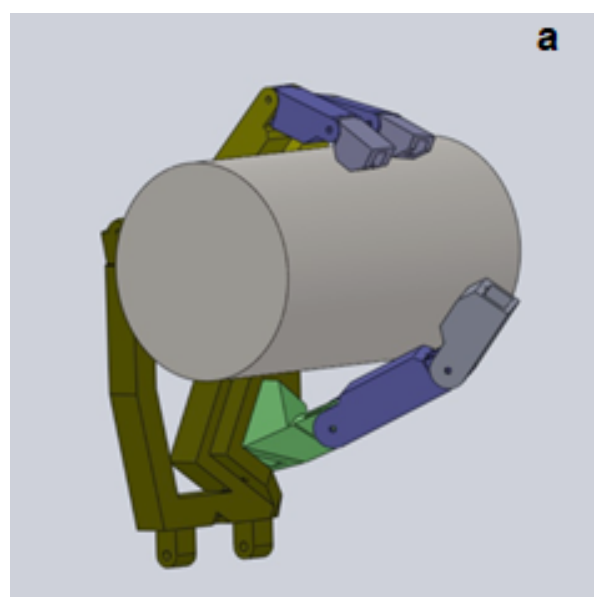

a

Fig. 8. Tridigital gripper $(a, b)$. Solid Works ${ }^{\circledR}$.
Figure 7 shows the CAD hand design (Figure 7a) and the sequence of movements for the grip (Figures $7 b, 7 c$, and $7 d$ ).
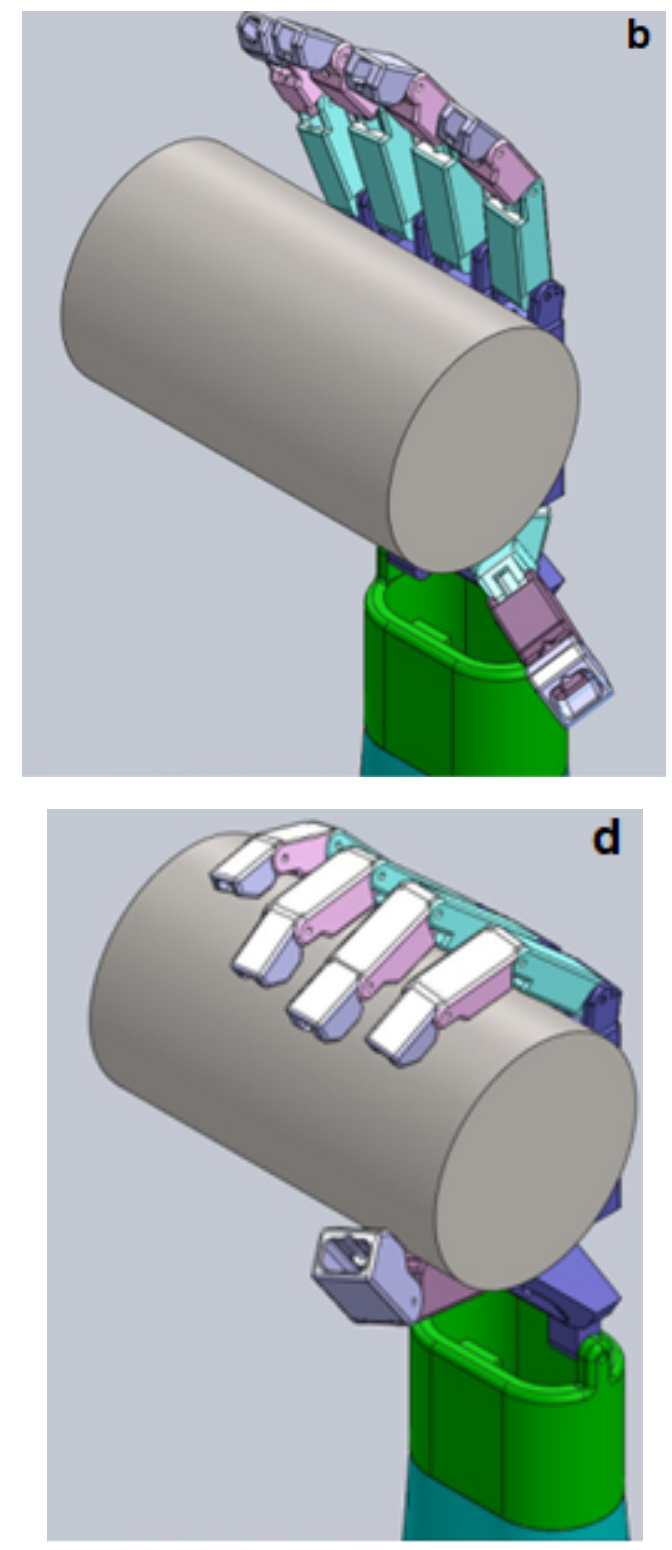

d

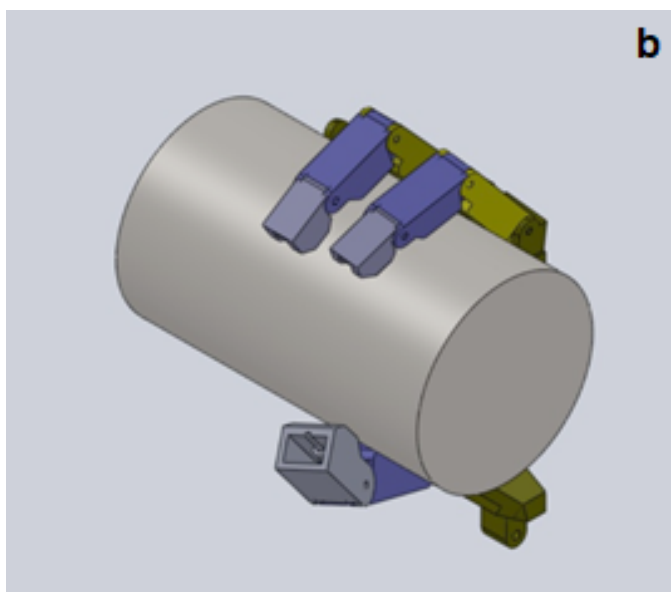




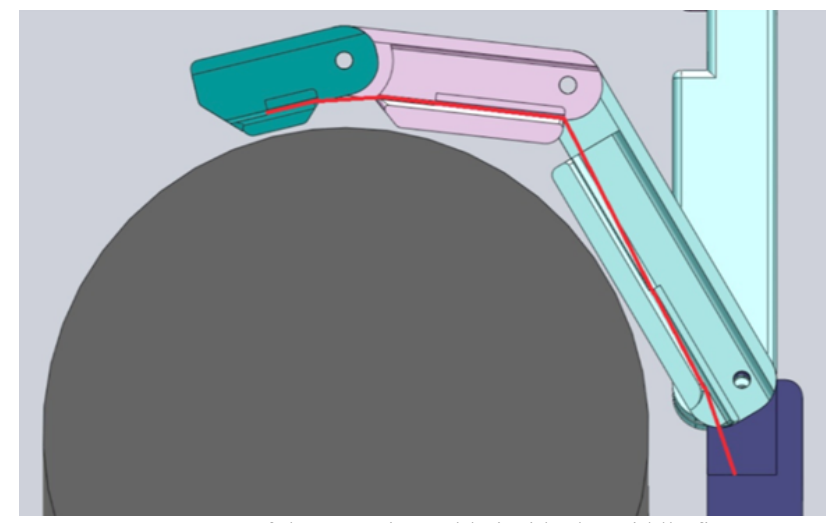

Fig. 9. Arrangement of the actuating cable inside the middle finger. Solid Works ${ }^{\circledR}$.

Since the fingers are driven by cables that are driven by motors, the forces exerted by the cables at the points of contact on the phalanges will be taken into account in the gripping process. Figure $8 \mathrm{~b}$ shows how the actuator cable is located and what is the location of the points of support of this on the phalanges that make up the finger. It was decided to place the forces directly on the points of support on each phalanx and thus to determine the developed efforts, due both to the contact with the cylindrical object and to the contact with the cable. Figure 10 shows the simulation results for the distal phalanx of the index finger, the tensile force on the cable is $30 \mathrm{~N}$ which is broken down into two rectangular components, one parallel to the longitudinal axis of the phalanx and the other perpendicular to it.

It can be observed that the greatest stresses are those generated in the support zone of the pins, while, compared to the latter, those located in the contact zone with the cylinder are significantly lower. Until now, the material selected for the manufacture of the prosthesis responds sufficiently to the applied loads since according to the analysis the maximum effort developed in the phalanx is $2.8 \mathrm{MPa}$ which is well below the 139.1 MPa that is the value of the elastic limit of the material referenced in Table 1. Figure 10 shows the analysis for the medial and proximal phalanges of the index finger. As in the case of the distal phalanx, the highest value stresses are generated in the support areas of the pins, but are still well below the elastic limit of the material.
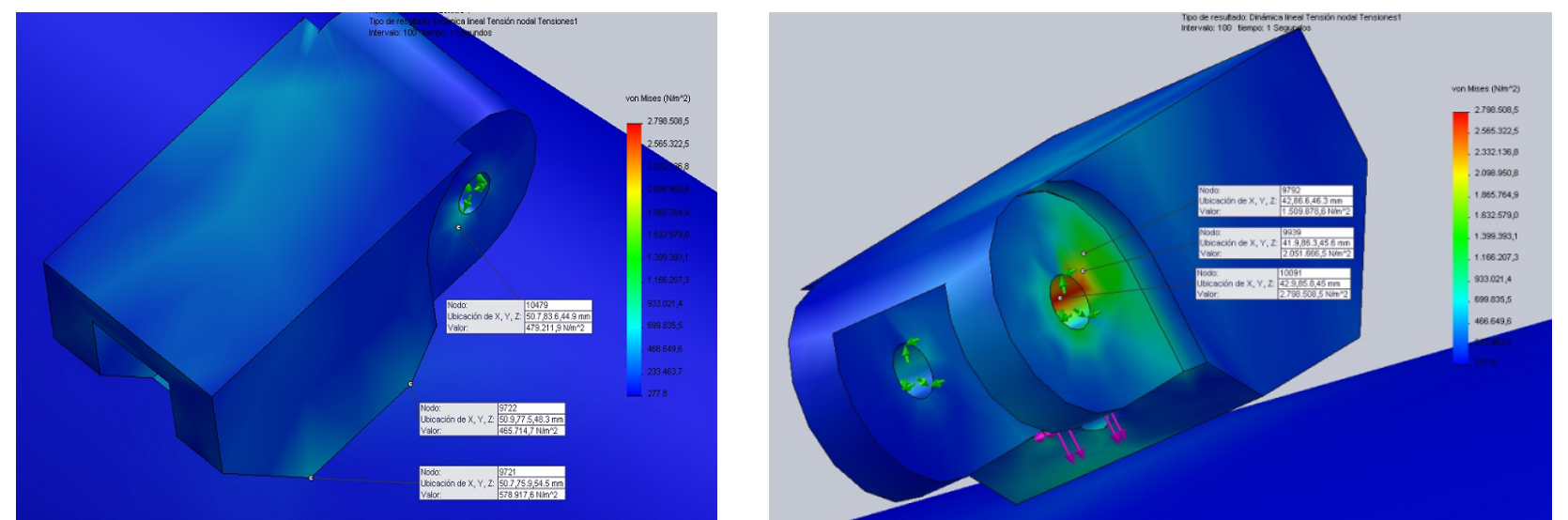

Fig. 10. Forces generated on the distal phalanx of the index finger by the action of the force applied by the cable and by contact with the cylinder. Solid works ${ }^{\circledR}$.
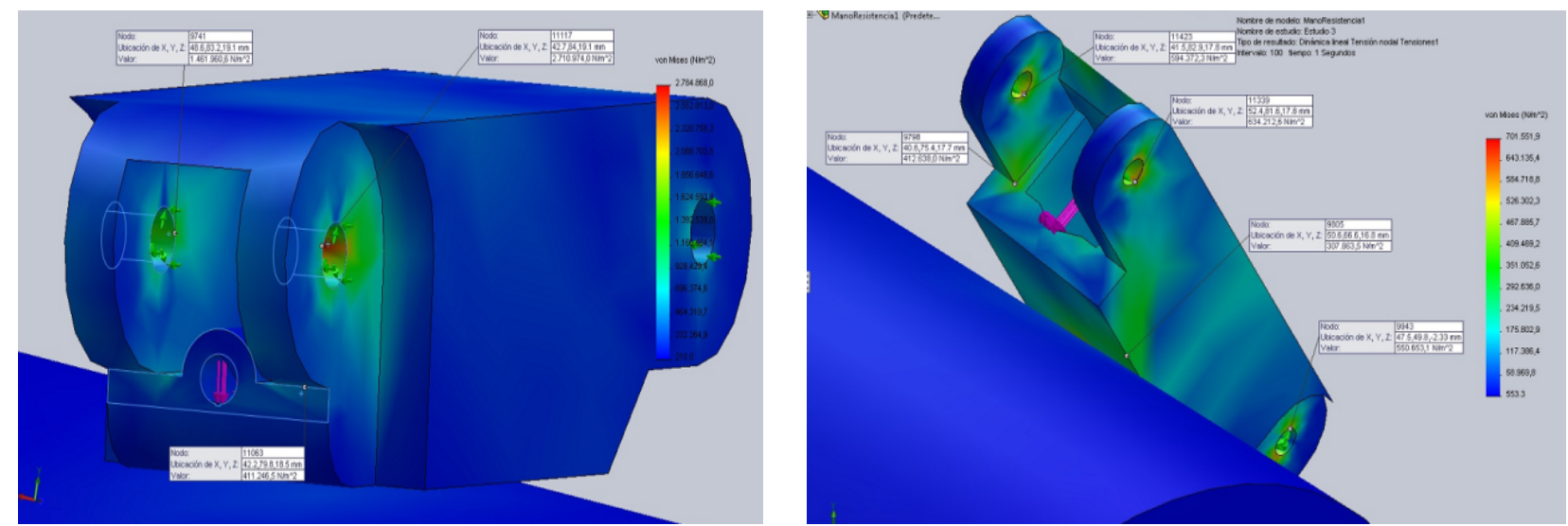

Fig. 11. Forces generated on the medial and proximal phalanges of the index finger by the action of the force applied by the cable and contact with the cylinder. Solid Works ${ }^{\circledR}$.

In the case of the middle finger, the behavior of the distal phalanx is very similar to that observed in the index finger, i.e., the highest stress values are located in the support area of the pin that articulates the distal phalanx with the medial, showing a value of $1.05 \mathrm{MPa}$, which is still well below the elastic limit of the selected material (Nylon 6/10). However, the same behaviour does not occur in the medial phalanx, since it is observed that the highest stress value is present in the area where the actuating cable rests on the phalanx. This is due to the configuration of the grip, which causes the middle phalanx of the middle finger not to come into contact with the cylindrical object; In addition, the relative angle of inclination between the medial and proximal phalanx is more closed than in the case of the distal and medial phalanx, therefore the component of cable tension in the direction perpendicular to the longitudinal axis of the phalanx is much 
higher, finding that the stress at the point of cable support reaches $72.5 \mathrm{MPa}$, about half of the elastic limit of the material. For the proximal phalanx, which, if it comes into contact with the steel cylinder, the maximum stress values again decrease to the levels observed in the distal phalanx, and its location agrees with the analysis so far enunciated, i.e. in the support area of the articulation pins between the phalanxes. The value of the maximum effort achieved in this phalanx for the load configuration used is $1.28 \mathrm{MPa}$, and is located in the hole for the articulation pin of this phalanx with the piece that emulates the metacarpal structure (palm of the hand).

The results of the resistance analysis of thumb materials are now shown. Figures 11 show the distribution of the stresses in the distal phalanx of this finger for the $30 \mathrm{~N}$ tensile force that has been assumed applied by the actuating cable.

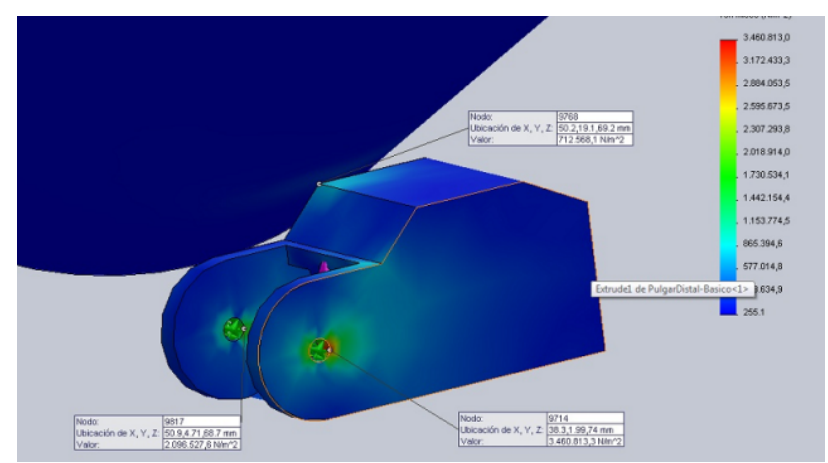

Fig. 11. Forces generated in the distal phalanx of the thumb. Solidworks ${ }^{\circledR}$.

As in previous cases where the phalanx comes into contact with the cylindrical object, the maximum stress values are located in the support area on the pin of the joint, for this case the maximum value corresponds to $3.5 \mathrm{MPa}$, which is still well below the elasticity limit of the material. The medial and proximal phalanges of the thumb do not come into contact with the cylinder for the grip configuration analyzed here. In addition, the proximal phalanx is designed in such a way that it helps with the positioning of the finger as a whole, but it is not directly affected by the actuating cable since the actuating cable practically does not rest on it. In the case of the distribution of forces in the medial phalanx of the thumb, it is observed that in this case the maximum stress values are located in the support zones of the articulation pins, even though the phalanx does not come into contact with the cylindrical object. The stress values are much higher than in the other fingers and this is in accordance with the physiology of the hand, for which it is stated that $40 \%$ of the force of the tridigital forceps is performed by the thumb. It is observed that the value of the efforts in the support zone of the pins reaches $47.3 \mathrm{MPa}$, about a quarter of the elastic limit of the material with which the prosthesis is simulated.

\section{b. Generation of the Functional Prototype}

Figure 12 shows the functional prototype of the Promanu prosthesis proposed in this document, which was constructed using the technique of rapid prototyping by means of UV light-cured resin. The result is equal to the CAD design and elaborated in Solidworks ${ }^{\circledR}$ (Figure 7a). In addition, it fully coincides with the vector kinematic approach, as it possesses the six degrees of freedom that were implemented in the Matlab ${ }^{\circledR}$ model. This prototype is in the testing and fitting phase. With respect to the actuators recommended for the operation of the prosthesis, direct current gear motors with a torque limit of $0.135 \mathrm{Nm}$ are recommended.
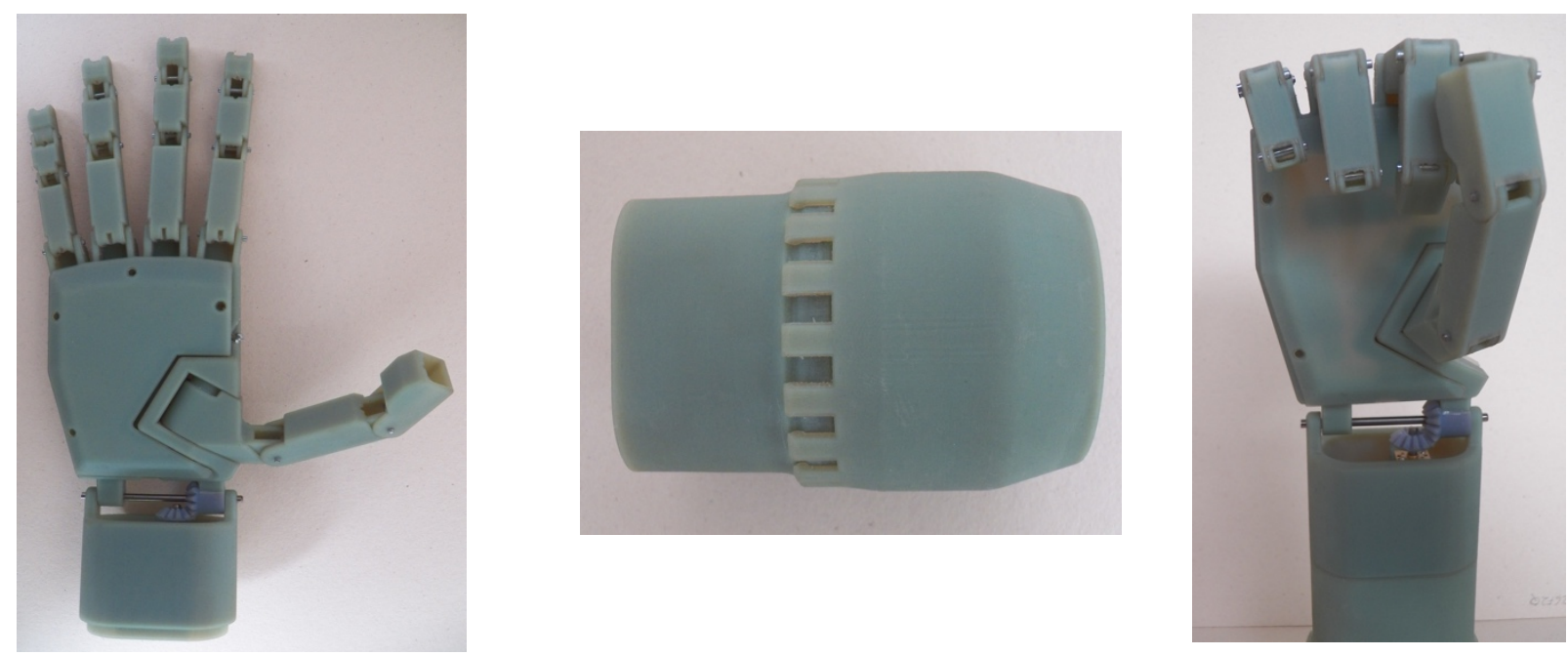

Fig. 12. Functional prototype of the Promanu hand prosthesis built with the Rapid Prototyping technique in photosensitive resin.

\section{Conclusions}

This work takes as its starting point the premises and design considerations obtained in a preliminary design stage of the hand prosthesis, where an exhaustive work was carried out to search for user requirements, engineering specifications and functions for this device.

The total kinematics of the hand prosthesis is developed by means of transformation matrices that help to define the positioning of the different links that make up the mechanism with respect to a global reference system. The above, in order to be able to describe several basic postures and grips. The materials selected during the mechanical strength analysis guarantee the necessary strength and stiffness for all designed components of the hand and forearm of the prosthesis.

The solids model is carefully crafted to care for the anthropometry and spatial arrangement of the prosthesis components. It should be noted that the Promanu hand prosthesis has a great geometric and dimensional resemblance to the hand of an adult person, has a thumb opposable to the rest of the fingers and its six degrees of freedom make possible a wide range of postures and grips, such as: pointing 
with the index; palm push, fan, tridigital forceps (fine grip), pentadigital grip (rough grip of a body approximately cylindrical or spherical).

As future work defines the need to implement a robust control system that allows, through myoelectric or voice signals, to reach the movements or postures mentioned. For this purpose, we suggest the implementation of transducers that record the angular position of the kinematic joints and the pressure in the buds of the phalanges.

\section{Acknowledgement}

The authors are grateful for the support provided by the Research Directorate of the Bogotá Headquarters of the National University of Colombia through the funding of the Research Project entitled "Design and construction of a functional prototype of a bioinspired hand prosthesis with five degrees of freedom (code 12017)".

This is an Open Access article distributed under the terms of the Creative Commons Attribution License

\section{(c) (P) $\$$}

\section{References}

[1] R. P. DORADOR J. M., «Robotica y protesis Inteligentes,» Revista Digital Universitaria, pp. 1-15, 2004.

[2] B. C. BARRIENTOS A., Fundamentos de Robotica, Mexico D.F.: Mc Graw Hill, 2007.

[3] G. R. L. C. FU S., Robotica: Control, Deteccion, Vision e Inteligencia, Mexico D.F.: Mc Graw Hill, 1998.

[4] C. M., «The CyberHand: on the design of a cybernetic prosthetic hand.,» de International Workshop on Humanoid and Human, Pontedera (PI), Italy, 2003.

[5] Q. B., «Diseño y Construcción de la Prótesis Robótica de Mano,» Ingeniería y Universidad, vol. 14, no 0123-2126., 2010.
[6] A. E. VIVAS A., Modelado Geométrico y Dinámico de una Prótesis de Mano Robótica, Popayan, Cauca, Colombia: Universidad del Cauca, 2003.

[7] TOUCHBIONICS, «www.touchbionics.com,» July 2008. [En línea]. [Último acceso: 112 2015].

[8] Ottobock, «www.ottobock.com,» Ottobock, 112 2015. [En línea]. [Último acceso: 5 2012].

[9] I. d. N. A. DIN (Deustches Institut fur Normung, Norma DIN 33 402, 2004. 